\title{
Modeling of the Production of Agrarian Products under the Conditions of Influence of Droughts, Rainfall and their Combinations
}

\author{
Yaroslav M. Ivanyo, Sophia A. Petrova, Marina N. Polkovskaya, Nina I. Fedurina \\ Department Of Informatics And Mathematical Modeling, \\ Irkutsk State Agricultural University named after A.A. Ezhevsky \\ Irkutsk, Russia \\ E-mail: sofia.registration@mail.ru
}

\begin{abstract}
The article presents the results of assessing the variability of extreme events, which include droughts and rainfall. The statistical properties of long-term series of maximum daily precipitation and yield of grain crops are determined. It is shown that the maximum daily precipitation affecting water erosion can be described by the Pearson type III distribution law, and the soil erosion potential by the truncated gamma distribution. Examples of risk assessment as a result of water erosion affecting the productivity of agricultural crops are given. The methodology of calculating damages and insurance compensation from drought effects is considered. Groups of models that make it possible to assess the variability in yields of cereals are selected. In some cases, it is possible to use regression models of the relationship of the effective trait with factors, time and previous values, and in others, the probability distribution laws with and without autocorrelation constraints. The example of a combination of extreme events in one year - a drought and a shower is given. To plan the production of agrarian products, we propose extreme tasks for one unfavorable climatic event and a combination of two events. The resulted models are realized for the agricultural enterprise of Irkutsk district. The proposed algorithms and models allow solving the problems of choosing the most acceptable control option in the conditions of drought and rainfall manifestations.
\end{abstract}

Keywords: Mathematical modeling, agricultural production, risks, drought, rainfall, combination of events.

\section{Introduction}

Significant damage to the agriculture of the Irkutsk region is caused by natural and man-made events $[3,6$, 10, 21, etc.]. Among them, for consideration, we will distinguish rainfall and droughts. The impact of rainfall on agriculture is: destruction or damage to crops; the formation of rain floods, flooding and under-heating agricultural land; damage to buildings; destruction of soil cover, etc.

In turn, dry phenomena reduce the yield of various crops; contribute to the deterioration of economic performance and stable activity of the commodity producer.

Risk management in conditions of rainfall and droughts contributes to better planning of agricultural production, improves management efficiency due to the correct choice of the solution of the problem on the basis of methods of mathematical programming.

The purpose of the study is to determine the damage to agricultural production by showers and droughts in various natural and climatic territories for risk management using optimization models.
In accordance with the goal, the following tasks are defined:

- assessment of damage from rainfall;

- assessment of damages from droughts;

- identification of risks associated with a combination of extreme climatic phenomena;

- planning the production of agricultural products in conditions of risks to rainfall and droughts.

In work methods of the theory of probability and mathematical statistics; mathematical programming in conditions of incomplete information are used.

\section{Assessment of damage from rainfall}

Preservation of soil fertility is one of the important priorities in the development of agricultural production [16]. In particular, one of the main tasks of the state program of the Irkutsk region "Development of agriculture and regulation of markets for agricultural products, raw materials and food for 2014-2020" is to increase the productivity, sustainability of agricultural production and soil fertility through integrated land improvement. This task is put in the basis of the 
subprogram "Development of Land Reclamation of Agricultural Land in the Irkutsk Region for 20142020".

Meanwhile, in the Irkutsk region, the activities of agricultural commodity producers are subject to the influence of various extreme hydrometeorological phenomena, among which we distinguish rainfall and droughts.

Storm precipitation causes damage to agriculture and the population in significant amounts. At the same time, they affect various aspects of human economic activity: they cause floods flooding and flooding populated areas and agricultural lands; they destroy crops; promote water erosion of soil; change the habitat of local fauna and flora, etc.

The rainfall as consequences of various adverse impacts, like other extreme climatic phenomena [6], increases the risks of crop production [10]. According to [6], the hailstones have a direct effect on crops, destroying them. Its share in total losses from natural phenomena is $6 \%$ for the region. It should be borne in mind the decrease in soil fertility as a result of wind and water erosion.

According to the results of modeling the potential flushing of the soil by rainwater over the past 50 years in the Irkutsk, Usol'e and Tulun districts is $4-10 \mathrm{~cm}$. Obviously, soil destruction contributes to a decrease in crop yields, and, consequently, to an increase in the natural risks of agricultural production.

A statistical analysis of the variability of rainfall over a long period is given in [19]. It is shown that the largest daily precipitation is a random variable and can be described by the Pearson III probability distribution law. According to the data of the three listed districts of the Irkutsk region, the average values of the meteorological parameter in question correspond to 21$24 \mathrm{~mm}$. At the same time, the maximum daily precipitation for a long-term period was 101-114 mm with the probability of occurrence of 0.0069-0.010.

In continuation of these studies, it was proposed to determine the potential washout of the soil from rainwater, assess risks from water erosion and economic losses in three agricultural regions: Irkutsk, Usolsky and Tulun.

Various methods for determining water erosion have been proposed in the literature, the main ones of which are based on methods - comparative-geographic, comparative-analytical and mathematical modeling [12, 20, etc.].

To assess the damage from water erosion for each district of the Irkutsk region, the following algorithm was used:
1) the potential washout of the soil from rain during the warm period of the year is calculated according to the method proposed in [12];

2) the statistical parameters of the long-term values of potential soil washout are calculated;

3) the laws for the distribution of probabilities of potential flushing of the soil are determined and constructed;

4) the damage caused by water erosion is calculated.

According to the autocorrelation analysis, it is shown that the series do not have significant autocorrelation coefficients and are random sequences.

Based on the estimation of the statistical parameters of the series of potential erosion of soil $E_{\mathrm{n}}$, calculated by the method of moments from data for 1968-2016, it is shown that the series have a high variation $\left(C_{v}\right)$ and are asymmetric $\left(C_{s}>0\right)$. Table 1 shows the average value of a multi-year series of potential rain washouts of soil ( $\left.\bar{E}_{n}\right)$ during the vegetation period, the coefficients of variation and asymmetry, as well as the minimum and maximum values of the parameter $\left.E_{n}^{\min }, E_{n}^{\max }\right)$.

Table 1. Potential rain washout of soil according to rainfall, morphometric and soil parameters of Irkutsk region.

\begin{tabular}{lccccc}
\hline $\begin{array}{c}\text { Municipal } \\
\text { district }\end{array}$ & $\begin{array}{r}\bar{E}_{n}, \\
\mathrm{~T} / \mathrm{ha}\end{array}$ & $C_{v}$ & $C_{s}$ & $\begin{array}{c}E_{n}^{\min }, \\
\mathrm{T} / \mathrm{ha}\end{array}$ & $\begin{array}{c}E_{n}^{\max }, \\
\mathrm{T} / \mathrm{ha}\end{array}$ \\
\hline Irkutsk & 19,8 & 1,50 & 2,81 & 0,58 & 146 \\
Usol'e & 13,4 & 1,54 & 3,72 & 0,73 & 122 \\
Tulun & 8,70 & 1,57 & 3,80 & 0,60 & 77,4 \\
\hline
\end{tabular}

According to the properties of the laws of probability distribution, the soil washout parameter obeys the truncated law of gamma distribution. Attention is drawn to the large values of the variation coefficient $C_{v}$ of the series of potential rain flushes of soil.

The territory of the Irkutsk region is most vulnerable to water erosion The largest washout of soil was observed in 1994, amounting to $146 \mathrm{t} / \mathrm{ha}$, and the minimum in 1977 was $0.6 \mathrm{t} /$ ha.

The agricultural lands of the Usolsky district are less affected by the water erosion of the soil. The maximum washout value took place in 2004 and amounted to $122 \mathrm{t} / \mathrm{ha}$, and the minimum in 2013 was $0.7 \mathrm{t} / \mathrm{ha}$.

In the Tulun district just as in Usolsky, the effect of water erosion is less than in Irkutsk. The variation of the parameter was 0.6-77.4 $\mathrm{t} / \mathrm{ha}$.

Analytical laws of the distribution of the probabilities of potential washout by storm precipitation 
of soil in the form of a truncated gamma distribution make it possible to estimate the repeatability of the specified flushing values, which can be used to determine risks (table 2).

Table 2. Damage to crops of municipal districts of Irkutsk region.

\begin{tabular}{cccccc}
\hline $\begin{array}{c}\text { Municipal } \\
\text { district }\end{array}$ & $\begin{array}{c}x_{\max }^{\max } \\
m m\end{array}$ & $p$ & $\begin{array}{c}Y_{n}, \\
m m\end{array}$ & $W, h a$ & $\begin{array}{c}D \text {, thousand } \\
\text { roubles }\end{array}$ \\
\hline \multirow{2}{*}{ Irkutsk } & \multirow{2}{*}{114} & 0,5 & 0,81 & 34058 & 4077,36 \\
& & 0,00025 & 14,6 & & 73493,08 \\
Usol'e & \multirow{2}{*}{108} & 0,5 & 0,52 & & 2833,12 \\
& & 0,0010 & 12,1 & 36862,7 & 65924,52 \\
Tulun & \multirow{2}{*}{101} & 0,5 & 0,32 & 55567,1 & 2628,10 \\
& & 0,0087 & 7,3 & & 59953,57 \\
\hline
\end{tabular}

Taking into account losses in the form of 1478 rub./ha from a decrease soil layer $Y_{p}$ by $1 \mathrm{~cm}$ as a result of erosion [24], economic losses are calculated. Analyzing the obtained results, we note that when moving from south to north, the values of the parameter $E_{n}$ decrease from 19.8 to $8.7 \mathrm{t} / \mathrm{ha}$, and for maxima from 146 to $77.4 \mathrm{t} / \mathrm{ha}$. Thus, the above laws of probability distribution of the potential washout of the soil by rainwater allow us to estimate the probability $p$ of given values of $E_{n}$ that can be used to determine the risks. The damage caused by the fall in the yield of grain crops in $W$ areas (Table 2) is calculated. The given loss values $D$ correspond to probabilities 0.5 and values characterizing the maximum possible damage from rare rainfall, repeated with an estimated probability of less than 0.01 . The parameter $Y_{n}$ represents the potential washout of the soil layer.

To this we should add that the resulted probabilities of the greatest potential washout of soil by rainwater are underestimated due to climate changes. In other words, as a result of warming trends, the likelihood of strong rainfall increases.

\section{Definition of damage from drought}

As a result of the statistical analysis of the yield of wheat over a long period in the municipal districts of the Irkutsk region, according to the criterion for the transition of the parameter value into an event, the probability of occurrence of arid phenomena is determined.

For their adequate estimation algorithms of converting sequences with trends and autocorrelation links to homogeneous samples were used.
Determination of damages from droughts was proposed in the article [21], in which homogeneous territories were previously singled out for the synchronism of long-term fluctuations in the yield of wheat according to the data for 1996-2015. The algorithm for allocating areas was as follows. Based on the matrix of correlation coefficients, groups of regions with links of not less than $0.70 \quad(R \geq 0.70)$ were determined. When the same areas were in different homogeneous territories, the value of the correlation coefficient was taken into account. The municipal district belonged to the territory for which the links between yields were higher. And, at last, a part of municipal areas is connected to a homogeneous zone on the basis of the most close connection in relation to other areas. Thus, four groups of homogeneous territories are distinguished.

In [9] prompted the development of techniques zoning Irkutsk region in probability manifestations drought according to [21] and calculated insurance cost wheat crop loss dimensions (destruction) of the crop, the percentage killed harvest to one of the municipal areas included in the selected group, meaningfully probability of drought and methodology. Calculations were carried out for the conventional crop area of wheat 1000 hectares. The average selling price of grain, developed by the Russian Federation, the subject of the year preceding the conclusion of agricultural insurance contract, according to the Federal state statistics service, amounted to 1 thousand. rub. / c [18].

According to the calculated average yields of wheat in the five years preceding the insurance year (c / ha), the insurance value of the wheat crop (thousand rubles) was determined, the amount of loss (death) of the wheat crop was calculated and the share of the depleted crop was obtained (Table 3.).

On the basis of the obtained results, it can be concluded that the lowest loss of wheat yield from the manifestation of drought is observed in the Usol'e district $(28.6 \%)$. Slightly more damage was recorded in the Tulun district $(29.1 \%)$. At the same time, in both these regions the criterion of insurance indemnities was not exceeded The Irkutsk region is particularly distinguished. For him, the estimated insurance indemnities exceeded 8 million rubles, and the share of the dead crop compared to the average was $42.2 \%$. According to the law of probability distribution of Pearson III type, a similar phenomenon is observed approximately 1 time in 17 years. 
Table 3. Calculated losses and insurance values of wheat yield according to data of three districts of Irkutsk region.

\begin{tabular}{|c|c|c|c|}
\hline \multirow{2}{*}{ Index } & \multicolumn{3}{|c|}{ Municipal district } \\
\hline & Irkutsk & Tulun & Usol'e \\
\hline $\begin{array}{l}\text { Average wheat yield in the region for the five years } \\
\text { preceding the dry year, centner / ha }\end{array}$ & 19,2 & 18,7 & 24,8 \\
\hline Planned harvest, centners & 19220 & 18720 & 24800 \\
\hline Insurance value of wheat harvest, thousand rubles. & 19220 & 18720 & 24800 \\
\hline Harvest of the dry year, centers & 11100 & 14500 & 21100 \\
\hline Share of lost crop, $\%$ & 42,2 & 29,1 & 1.5 \\
\hline Estimated insurance indemnities, thousand rubles. & 8120 & - & - \\
\hline
\end{tabular}

The results obtained for the yield of barley (Table 4) show that there is practically no loss of yield in the Tulun district. At the same time, in the Usol'e district it was $29.4 \%$. The highest yield losses of barley, as well as wheat, are observed in the Irkutsk district - $64.3 \%$. At the same time, the estimated insurance indemnities amounted to 12.1 million rubles.

Table 4. Calculated losses and insurance values of barley harvest according to data of three districts of the Irkutsk region.

\begin{tabular}{|c|c|c|c|}
\hline \multirow{2}{*}{ Index } & \multicolumn{3}{|c|}{ Municipal district } \\
\hline & Irkutsk & Tulun & Usol'e \\
\hline $\begin{array}{l}\text { Average wheat yield in the region for the five years } \\
\text { preceding the dry year, centner / ha }\end{array}$ & 18,76 & 17,42 & 25,06 \\
\hline Planned harvest, centners & 18760 & 17420 & 25060 \\
\hline Insurance value of wheat harvest, thousand rubles. & 18760 & 17420 & 25060 \\
\hline Harvest of the dry year, centers & 6700 & 17400 & 17700 \\
\hline Share of lost crop, \% & $64,3 \%$ & $0,1 \%$ & $29,4 \%$ \\
\hline Estimated insurance indemnities, thousand rubles. & 12060 & - & - \\
\hline
\end{tabular}

When analyzing the damage from drought for oat crop yield (table 5), the Tulun district is especially prominent, in which the yield in the dry year was $10 \%$ higher than the average.
A slight deviation from the average is typical for the Usol'e district. In the Irkutsk district, on the contrary, the yield was almost twice lower than the average, which in monetary terms is estimated at 8.4 million rubles.

Table 5. Calculated losses and insurance values of oats harvest according to data of three districts of Irkutsk region.

\begin{tabular}{lccc}
\hline \multicolumn{1}{c}{ Index } & \multicolumn{2}{c}{ Municipal district } \\
& Tulun & Usol'e \\
\hline $\begin{array}{l}\text { Average wheat yield in the region for the five years preceding } \\
\text { the dry year, centner / ha }\end{array}$ & 17,16 & 18,52 & 21,85 \\
Planned harvest, centners & 17160 & 18520 & 21850 \\
Insurance value of wheat harvest, thousand rubles. & 17160 & 18520 & 21850 \\
Harvest of the dry year, centers & 8800 & 20400 & 20900 \\
Share of lost crop, \% & $48,7 \%$ & - & $4,3 \%$ \\
Estimated insurance indemnities, thousand rubles. & 8360 & - & - \\
\hline
\end{tabular}

Note that the damage is determined by the frequency of drought. According to the analysis of the average yield of grain crops in the five years preceding the insurance year, the Irkutsk district is most exposed to droughts, yield losses in which, depending on crops, amounted to $42.2-64.3 \%$. Tulun and Usol'e districts are less dependent on the effects of droughts, the damage from loss of crop did not exceed the criterion of insurance reimbursements. To reduce losses, the correct redistribution of funds and an effective insurance policy are necessary.

\section{The combination of rainfall and droughts in the problem of damage assessment}

In $[4,10]$ conducted a study on the formation of different origin climatic events in one year. It is shown that in some years there are two climatic extremes that 
cause damage to agriculture, which exceed the values of losses from the impact of one rare event.

As a rule, droughts are associated with the parameters of humidification and heat, which include precipitation and air temperatures $[8,13]$.

Based on the correlation-regression analysis of the dependence of grain crop yields on hydrometeorological factors, taking into account time and autocorrelation relationships, models are obtained that describe the degree and signs of the relationship between the effective trait and the main parameters. The simulation results showed that five groups of models can be used to estimate crop yield variability: trend, autoregressive, trend and autoregressive, factorial and factor models, taking into account trends and autocorrelation relationships. A generalized function characterizing the relationship between the effective sign of $y_{t}$, the hydrometeorological factors $z_{i}$, the time $t$, and the preceding values of $y_{t-\tau}$ can be written in the form

where $i \in I, \tau \in \mathrm{T}$

$$
y_{t}=f\left(z_{i}, t, y_{t-\tau}\right),
$$

It is clear that the reduced function is regressive and can be either linear or non-linear.

Results of application of various groups of models allowed to reveal the following regularities:

- in many cases, for forecasting with a lead time of 1 year, it is possible to use trend models together taking into account the autocorrelation;

- for different of grain crops, various factor models are applied, taking into account trends, reflecting the characteristics of culture;

- expressions describing the variability of grain yields, which can be used for forecasting, are adequate, first of all, for Usol'e district;

- in the south, the yield of cereals is heavily influenced by rainfall, and in the north, air temperatures have an additional effect.

In addition to the proposed mathematical expressions in many municipal districts of the Irkutsk district, the ranks of grain yields are random and loosely coupled samples.

Analyzing the formation in one year of dry phenomena and rainfall over the period 1996-2016, it can be concluded that 2015 was not only arid, but it differed in the impact of rainfall on the soil. According to the probability formula for two joint events $\left(p=p_{1}+p_{2}-p_{1} p_{2}\right)$, the probability value for extreme events (drought and rainfall) in the Irkutsk region was 0.30 . If the losses are summed up as a result of a drought and the soil is reduced by rain flushing by 2 $\mathrm{mm}$, the total amount of losses will amount to 38607.5 thousand rubles, in which $26.1 \%$ is caused by damage from the influence of rains.

In other areas, no double effect was observed with low probability.

\section{Management of risks of agricultural production in conditions of influence of downpours and droughts}

Natural processes are an integral part of the production of agricultural products, having a positive and negative impact on it. Therefore, the planning of agricultural production must be carried out taking into account natural risks.

Optimal plans for the production of agricultural products can be obtained with the help of mathematical programming. Various variants of such problems are realized on the examples of various agricultural objects of the Irkutsk region in $[3,5,7,10$, etc.].

In this paper, two optimization models for the planning of agricultural production are presented in a combination of crop and livestock production in the context of one and two extreme natural phenomena causing damage to agricultural production in the same year, with random parameters.

The first task involves the work of the economy in the context of the manifestation of one extreme natural phenomenon with random parameters, and the second several.

Both tasks of planning of production in the conditions of extreme events are solved by the example agricultural enterprise close corporation "Irkutsk Seeds" of the Irkutsk Region (table 6). In this case, the first model was implemented in conditions of rare drought, which manifested itself in 2015 in parts of the Irkutsk region. In another case, the optimization of the production of agricultural products under the conditions of the influence of rare rainfall observed in Irkutsk in the summer of 1994 was considered. 
Table 6. The results of solving the problem of mathematical programming for close corporation "Irkutsk seeds" Irkutsk district of the Irkutsk region in the averaged and extreme climatic conditions.

\begin{tabular}{|c|c|c|c|c|c|c|c|c|}
\hline \multicolumn{9}{|c|}{ Value of the required variable (production plan) } \\
\hline Task & 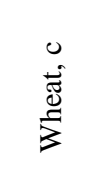 & $\begin{array}{l}0 \\
\tilde{\Xi} \\
ض \emptyset\end{array}$ & $\begin{array}{l}0 \\
0 \\
\tilde{0} \\
0\end{array}$ & 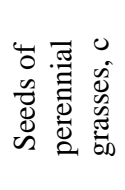 & $\begin{array}{l}0 \\
\dot{a} \\
0\end{array}$ & 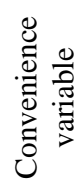 & $\begin{array}{l}\text { Revenue, } \\
\text { million rubles }\end{array}$ & $\begin{array}{l}\text { Damage relative } \\
\text { to planned } \\
\text { indicators, million } \\
\text { rubles }\end{array}$ \\
\hline Production targets & 40925 & 4154 & 85792 & 500 & 800 & 1 & 206,83 & - \\
\hline Given the rare drought & 23454 & 4154 & 77840 & 450 & 800 & 1 & 176,55 & 30,28 \\
\hline $\begin{array}{l}\text { In the conditions of extreme } \\
\text { rainfall }\end{array}$ & 40925 & 4154 & 85792 & 500 & 800 & 1 & 197,51 & 9,32 \\
\hline $\begin{array}{l}\text { Given the rare drought and } \\
\text { extreme rainfall }\end{array}$ & 23454 & 4154 & 77840 & 450 & 800 & 1 & 167,22 & 39,61 \\
\hline
\end{tabular}

In addition, the task is solved for the joint manifestation in the same year of extreme rainfall that leads to soil erosion, and a rare drought manifesting itself in the form of a significant decrease in crop yields.

According to the results of the task to determine the planned performance of production (table. 6), in the absence of extreme events, the revenue from agricultural production is about 207 million rubles. At the same time, the planned yield of agricultural crops was determined as the arithmetic average on the basis of the data of the bioproductivity of agricultural crops in the Irkutsk district for the period 2010-2014. A fiveyear period preceding the severe drought observed in the Irkutsk district in 2015 was chosen, which corresponds to the method of calculating losses of agricultural production [10].

In solving the problem, taking into account the severe drought, the actual data of crop bioproductivity in the Irkutsk district in 2015 were used. The probability of drought occurrence in the territory, according to the distribution of Pearson III, was 0.0583 , and the damage caused was more than 30 million rubles.

Heavy rains in the warm period can wash away the top fertile soil layer, which affects the productivity of crops and the need for mineral and organic fertilizers on cultivated areas. The work identified the damage caused by such a phenomenon, equal to the power of 1994 in Irkutsk, in which the value of the washed soil layer was $1.46 \mathrm{~cm}$, and the damage, for example, for wheat was about 1.5 thousand rubles/ha for each centimeter of the lost top fertile soil layer. In this case, the potential damage caused by an extreme rainfall amounted to more than 9 million rubles.

As for the manifestation of drought and heavy rain in the same year, the damage caused to the agricultural enterprise close corporation "Irkutsk seeds" is estimated at about 40 million rubles. (Table 6).

\section{Conclusion}

In work from a large number of the extreme climatic phenomena influencing activity of the agricultural producer, storm rainfall and droughts are considered. The first extreme phenomenon contributes to soil destruction, and the second greatly reduces the yield, while worsening the possibility of stable development of the agricultural enterprise.

To assess the destruction of soil by rain waters, a method for determining the potential washout is chosen, characterized by the parameters of the rainfall and the underlying surface. On the basis of calculations of potential soil washout by rain waters the laws of probability distribution in the form of truncated gamma-distribution are constructed to assess the frequency of adverse events. Losses from soil destruction by water erosion for averaged and unlikely events are calculated.

The damages associated with the influence of arid phenomena are determined. The results of the assessment of losses for three grain crops for three municipal districts of the Irkutsk region are presented. It is shown that in recent years the most unfavorable conditions for agriculture took place in the Irkutsk district. The amounts of insurance indemnities are found. The risks of the impact of dryland phenomena on agricultural production are estimated.

The models of agricultural production planning taking into account risks for one extreme phenomenon and a combination of two events of different origin are constructed. The models are implemented for one of the agricultural enterprises of the Irkutsk district, allowing the decision-maker to choose acceptable optimal plans of activity.

The proposed algorithms for risk assessment due to droughts and rainfall, and optimization models can improve the efficiency of agricultural production management in complex climatic conditions of the Irkutsk region. 


\section{References}

1. M. Astaf'eva and Ya. Ivan'o, Optimization of agricultural crops placement taking into account natural and economic features of the region, in Proc. XVI Baikal all-Russian conf. Information and mathematical technologies in science and management (Irkutsk, Russia, 2011), pp. 224-231.

2. M. Astaf'eva, Ya. Ivan'o and S. Petrova, Spatio-temporal regularities of climatic parameters variability and agricultural crops productivity in the south of Eastern Siberia, J. Ecological bulletin, 3 (25) (2013) 13-18.

3. A. Belyakova, Ya. Ivan'o and S. Petrova, On a model of parametric programming of agricultural production taking into account the manifestations of hydrological events, $J$. Actual questions of agrarian science, 19 (2016) 41-49.

4. A. Belyakova, E. Vashukevich, Ya. Ivan'o and S. Petrova, Trends in the variability of natural events in the south of Eastern Siberia, J. Bulletin of IrSTU, 10 (2014) 80-85.

5. N. Bendik, Ya. Ivan'o, About modernization of information system of modeling of natural events, in Proc. Int. Conf. Nature management and agricultural production (Irkutsk, Russia, 2012), pp. 166-172.

6. Vashukevich, Ya. Ivan'o and E. Trufanova, On the modeling of drought and their assessment criteria, in Proc. XII Baikal all-Russian conf. Information and mathematical technologies in science and management (Irkutsk, Russia, 2007), pp. 246-253.

7. E. Vashukevich and Ya. Ivan'o, Mathematical models of agricultural production with probabilistic characteristics of droughts and hydrological events (IrSAU, Irkutsk, 2012).

8. Р. Genkel' П.А., Physiology of heat and drought resistant plants (Science, Moscow, 1982).

9. Ya. Ivan'o, S. Petrova and M. Polkovskaya, Probabilistic assessment of the frequency of occurrence of droughts and identification of risks of agricultural production, $J$. Bulletin of IrSTU, 4(135) (2018) 73-82.

10. Ya. Ivan'o, S. Petrova, Optimization models of agricultural production in solving problems of natural and man-made risks assessment (IrSAU, Irkutsk, 2015).

11. Ya. Ivan'o and M. Polkovskaya, Optimization of crop structure taking into account the variability of climatic parameters and crop bioproductivity (IrSAU, Irkutsk, 2016).

12. G. Larionov, Erosion and deflation of soils: the main regularities and quantitative estimation (MSU, Moscow, 1993).

13. V. Loginov, A, Neushkin and E. Rogachev, Droughts, their possible causes and prerequisites for prediction (ARIHI-WCD, Obninsk, 1976).

14. V. Medvedev, A. Millerman and V. Shakhov, Theory and management of risks in insurance (Finance and statistics, Moscow, 2002).
15. A. Nikitin and A. Fedorenko, The economic mechanism of insurance and overcoming risks in agriculture in Russia when joining the WTO (FSBSI "Rosinformagroteh", Moscow, 2006).

16. On the approval of the state program of the Irkutsk region "Development of agriculture and regulation of markets for agricultural products, raw materials and food" for 2014-2020 (with changes as of December 15, 2017).

17. Estimate of the tariff for insurance of rare and catastrophic risks - [Electronic resource]. Access mode http://www.strahuemvseh.ru.

18. Order of the Ministry of Agriculture of Russia of November 16, 2017 No. 578 "On the approval of methods for determining the insurance value and the amount of loss (death) of crop yield and planting perennial plantations and methods for determining insurance value and the amount of loss (death) of farm animals."

19. V. P'yankova, Probabilistic estimation of variability of rainfall in the southern part of the Irkutsk region and its use in determining water erosion, in Proc. all-Russian conf. Scientific research of students in solving urgent problems of agroindustrial complex (Irkutsk, Russia, 2018), pp. 103-111.

20. G. Shvebs, Formation of water erosion of sediment runoff and their assessment: the example of Ukraine and Moldova (Hydrometeorological publishing house, Leningrad, 1974).

21. Ivan'o Ya. M. and N.S. Suvorkina, Modeling the repeatability of droughts and risks of agricultural production, in Proc. Int. Conf. Climate, ecology, agriculture of Eurasia (Ulaanbaatar, Mongolia, 2017), pp. 90-98.

22. T. McKee, N. Doesken and J. Kleist, The Relationship of Drought Frequency and Duration to Time Scales, in Proc. 8th Conf. on Applied Climatology (Anaheim, CA. Boston, MA, 1993).

23. A. Mishra and V. Singh, Drought modeling, J. of Hydrology, 403 (2011) 157-175.

24. N. Osmolovskaya, J. Shumilina, T. Grishina, A. Didio, E. Lukasheva, T. Bilova and A. A. Frolov Modeling of Drought in the Experiment and Assessment of its Effects on Plants, J. of Stress Physiology \& Biochemistry, 4 (2017) 110-120.

25. R.Pulwarty and M. Sivakumar, Information systems in a changing climate: early warnings and drought risk management, J. Weather and Climate Extremes, 3 (2014) $14-21$.

26. A. Zargar, R. Sadiq, B. Naser and F.I. Khan, A review of drought indices, J. Environmental Reviews, 19 (2011) 333-349. 